SANDIA REPORT

SAND95-2938 - UC-706

Unlimited Release

Printed February 1996
RECEIVED

HAY 151996

QS.T. I

\title{
The Future of Components for High Reliability Military and Space Applications
}

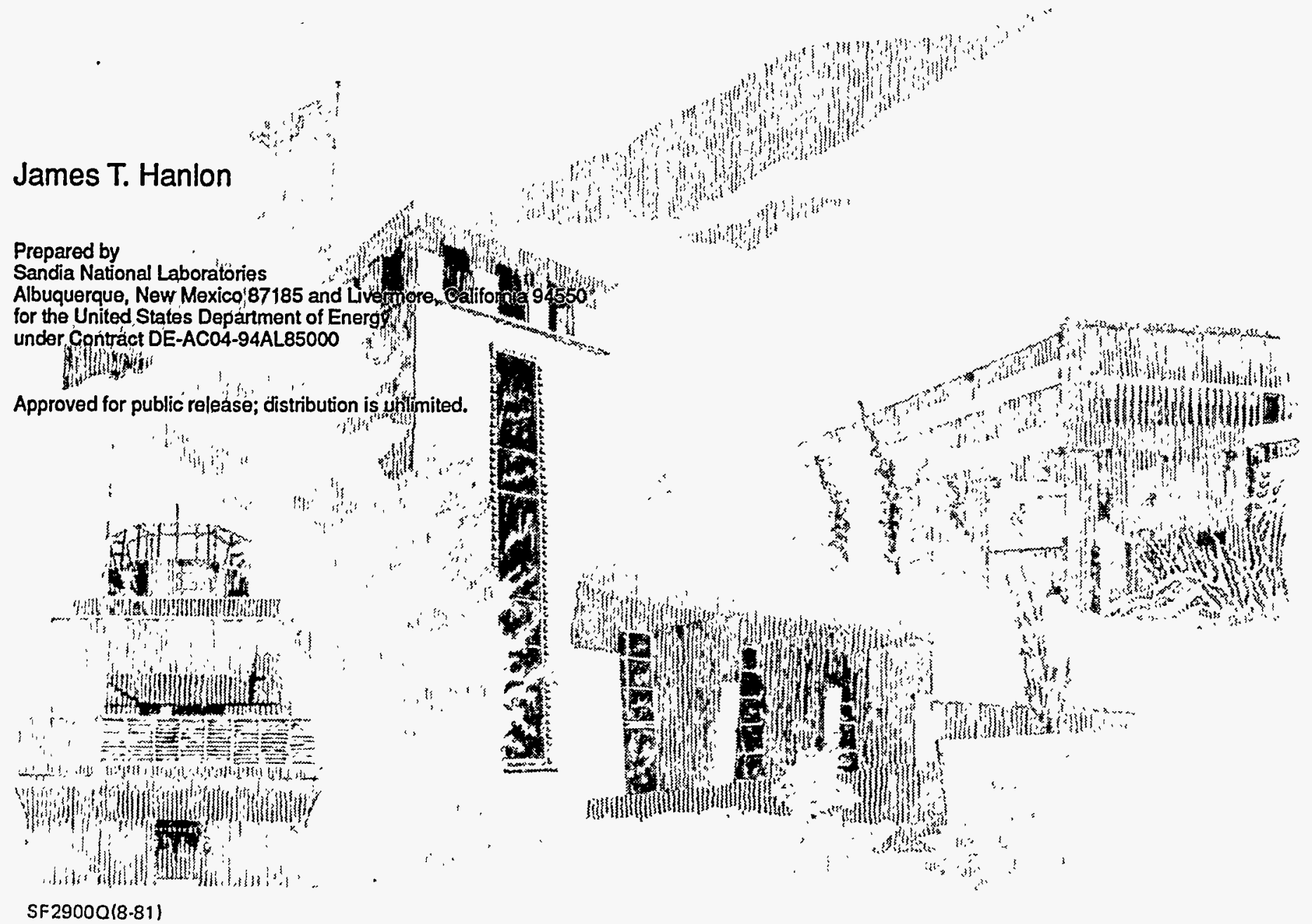


Issued by Sandia National Laboratories, operated for the United States Department of Energy by Sandia Corporation.

NOTICE: This report was prepared as an account of work sponsored by an agency of the United States Government. Neither the United States Government nor any agency thereof, nor any of their employees, nor any of their contractors, subcontractors, or their employees, makes any warranty, express or implied, or assumes any legal liability or responsibility for the accuracy, completeness, or usefulness of any information, apparatus, product, or process disclosed, or represents that its use would not infringe privately owned rights. Reference herein to any specific commercial product, process, or service by trade name, trademark, manufacturer, or otherwise, does not necessarily constitute or imply its endorsement, recommendation, or favoring by the United States Government, any agency thereof or any of their contractors or subcontractors. The views and opinions expressed herein do not necessarily state or reflect those of the United States Government, any agency thereof or any of their contractors.

Printed in the United States of America. This report has been reproduced directly from the best available copy.

Available to DOE and DOE contractors from

Office of Scientific and Technical Information

PO Box 62

Oak Ridge, TN 37831

Prices available from (615) 576-8401, FTS 626-8401

Available to the public from

National Technical Information Service

US Department of Commerce

5285 Port Royal Rd

Springfield, VA 22161

NTIS price codes

Printed copy: A03

Microfiche copy: A01 
SAND95-2938

Distribution

Unlimited Release

Category UC-706

Printed February, 1996

\title{
The Future of Components for High Reliability Military and Space Applications
}

\begin{abstract}
A representative survey of DOD Suppliers and their response to the Perry Initiative
\end{abstract}
James T. Hanlon

Component Information and Management Department

Sandia National Laboratories

Albuquerque, NM 87185-0525

\begin{abstract}
Military specified, ceramic packaged and radiation hardened components will disappear before the end of the century. The only long-term sustainable alternative may well be to use plastic packaged Commercial Components. The material in this report comes from the Defense Logistics Agency sponsored Plastic Package Availability Program and from an AT\&T field reliability study. It summarizes Case Studies from companies which have been building and fielding highly reliable commercial and DOD military systems using plastic commercial components. Findings are, that when properly selected commercial components are operated within the true limitations of their design and packaging, they are as reliable as today's Mil Spec components. Further, they offer cost, space and weight savings, shared manufacturing and field test experience with industry, and access to the most modern technology. Also reported are potential problems that may be encountered when using commercial components, their long term storage and use reliability . characteristics, recommended design processes and supplier selection practices, commercial best business practices, and a semiconductor manufacturer's view of the military's switch to commercial plastic microcircuits.
\end{abstract}




\section{Acknowledgment}

The Material reported herein is largely drawn from presentations made at the 1995 Advanced Technology, Acquisition, Qualification, And Reliability Workshop, August 15 to 17,1995 , sponsored by the DOD Tri-Service MIMIC Qualification Committee and from presentations made at the 1995 Sustainable Hardware and Affordable readiness Practices Program (SHARP), November 15 and 16, 1995, sponsored by the Naval Surface Warefare Center - Crane. The contributions of the speakers at this workshop and of several other sources interviewed by the author are identified and acknowledged in the text.

The author also wishes to thank Sandia reviewers David W. Peterson and David W. Palmer for their contributions and their encouragement. 


\section{Contents}

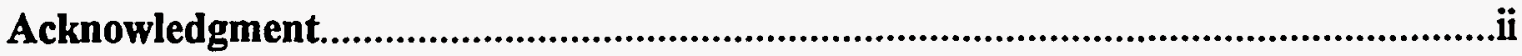

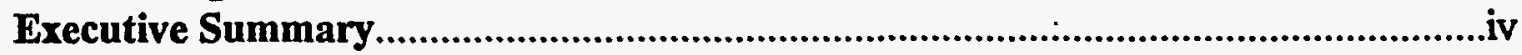

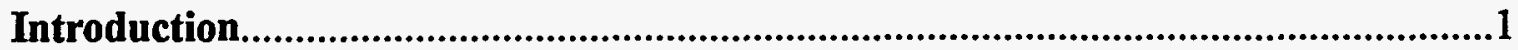

What's all this fuss about components? Let's just use upgraded Mil Spec components like we always have....................................................................1

Case Studies involving Field experience with Commercial Components........................3

Factory and Field Experience with AT\&T WP Components.....................................3

Honeywell Comparison of Field Reliability of Commercial Plastic IC's and

883B Ceramic IC's operated on Commercial Aircraft.....................................4

ITT's Commercial Parts Program Plan Implemented in

SINCGARS and MINTERM..............................................................6

General Dynamics Implements SINCGARS using Best Commercial Practices........6

Rockwell International, Collins Avionics Division, Uses Plastic Encapsulated

Microcircuits in Precision Lightweight Global Positioning Receiver..............6

Lucas Electronics Experience with Civil Engine Control reliability...........................7

Computing Devices International sees using commercial technology for military applications as a business necessity.....................................................7

MARTA Defense (France) has been using plastic parts since 1987

in Missile applications...................................................................................7

British Defense Research Agency, Space Department, will Investigate

COTS for Use in Spacecraft...........................................................................8

Incentives to use Commercial Components...............................................................8

Potential Problems with Commercial Components......................................................8

Long Term Storage and Use Reliability of Commercial Plastic Components..............9

Advanced Silicon Based Thin-Film Material Provides "Hermetic Seal" for

Semiconductor Devices................................................................................10

Recommended Design Process and Supplier Selection Guidelines

when Using Commercial Components.............................................................10

Lockheed/Martin Missiles System Division Recommended Design Process...........10

Honeywell Supplier Selection Guidelines................................................................11

DoD OEM's Supplier Evaluation Guidelines........................................................11

PPA Program, Recommended DO's...................................................................11

PPA Program, Recommended DON'T's.......................................................12

PPA Priority Sequence for Selecting Components ..................................................12

Adoption of Commercial Best Business Practices..........................................................13

A Semiconductor Manufacturer's View of the Perry Initiative

and the Military Switch to PEM's..............................................................14

Plastic Package Availability Program..................................................................15

And Finally, a Sandia Perspective...........................................................................16 


\section{Executive Summary}

Military specified, ceramic packaged and radiation hardened components will disappear before the end of the century. The only long-term sustainable alternative may well be to use plastic packaged Commercial Components. This paper, taken from material supplied by the Defense Logistics Agency sponsored Plastic Package Availability Program and from an AT\&T component field reliability study, presents information which will help Sandia designers understand more about whether and how to use commercial components in their designs.

Telephone, avionics, and automotive systems have been built from commercial components for decades and are highly reliable. Extensive ground based field data demonstrates that commercial components in both controlled and uncontrolled environments have FIT rates on the order of 0.1 to 3. (One FIT is one failure in $10^{9}$ operating hours.) Honeywell field life data comparing a commercial avionics system made both with Mil Spec 883B grade ceramic encapsulated parts and with commercial plastic parts has found that plastic parts are more reliable than ceramic parts. Lucas Electronics experience with commercial plastic parts in automotive environments and Mil Spec ceramic parts in very similar avionics environments shows them to have essentially the same reliability.

Suppliers of systems to the DoD have been successfully using commercial plastic components for several years. ITT has built and shipped SINCGARS and MINTERM, and has found the performance, quality and reliability of commercial components to be the equal that of military spec components. General Dynamics also is building SINCGARS and reports that Best Commercial Practice parts are as robust as their traditional military counterparts and result in from 50\% to $70 \%$ cost savings. Rockwell's Precision Lightweight Global Positioning Receiver made from surface mount, commercial plastic components has been in the field for two years. Overall worst case failure level is approximately that predicted by Mil Handbook $217 \mathrm{H}$, cost savings are 8.5 to 1 over Mil Spec parts, and unit size is smaller. Lucas Electronics (UK) has found that commercial plastic parts behave as well in their automotive electronics products as do ceramic, Mil Spec parts in their avionics control systems. They are evaluating plastic parts for their aerospace products. Computing Devices International is shipping computer systems made from commercial parts to the Navy for shipboard and airborne use. MATRA Defense, France, has been using plastic components since 1987 in missile applications. The British Defense Research Agency, Space Department, is investigating the use of commercial plastic components in spacecraft. A University of Maryland, CALCE study is at work to determine the effects of storage on plastic components in a variety of environments. They estimate that the life of components in warehouse storage exceeds twenty years.

Military and Aerospace OEMs report an order of magnitude cost savings with commercial components. New technology is available first, and often only, in commercial 
components. Systems are smaller, lighter and have greater capability, and they can be assembled on commercial manufacturing lines.

But commercial components have their own set of potential problems. They are not intentionally radiation hardened. They will often be required to operate beyond their specified temperature range (which they are for the most part capable of doing). Commercial parts will change in design and processing, as often as every 18 months. Commercial manufacturers will not readily accept source control drawings.

A set of Lockheed/Martin guidelines for using commercial components are presented. Supplier selection and evaluation guidelines are offered by Honeywell and other DOD OEM's and by the DoD sponsored Plastic Package Availability Program. Several Commercial best Business Practices from TRW, Honeywell and AT\&T are outlined in this report.

TI has provided a manufacturer's view of using commercial plastic components in military applications. There are 7800 integrated circuits currently available as Military QML parts, approximately 20 of which are plastic. Mil parts are rated over the full temperature range whereas commercial parts are not. Mil parts are the same as their commercial equivalents, most of the time. QML parts offer traceability, DESC certification of suppliers, obsolescence control, and better vendor support. Plastic surface mount parts require careful storage, handling and processing. Vendor selection is critical for plastic parts, not all suppliers are equal. The military component market, at $\$ 1.4$ billion per year, is still viable. (But another TI source says TI will drop their military microelectronics "in a heartbeat" if they become unprofitable.)

A Sandia Participant in the Plastic Package Availability Program offered the following perspective. Best Commercial Practices on plastic microcircuits have evolved so that we now have cleaner materials, less stress and six sigma wafer fabrication and packaging lines. Plastic parts are proving to be very reliable. There are greater problems with plastic packages than with hermetic packages, but they are all workable. Mil Specs are disappearing. We should go to Automotive and Aerospace users, see how they manage to use plastic parts, and learn from them. The next new DOE weapon system will contain commercial, plastic molded ICs. 


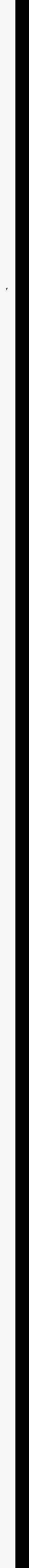




\title{
The Future of Components for High Reliability Military and Space Applications
}

\author{
A representative survey of DoD Suppliers and their response to the Perry Initiative
}

\section{Introduction}

\begin{abstract}
"We are short of money, therefore we must start to think." (Lord Rutherford as quoted by Maurice Chener of Computing Devices International at the SHARP conference)
\end{abstract}

What's all this fuss about Components? Let's just use upgraded, hermetically sealed. Mil Spec components like we always have.

Reality is that most if not all of the traditional, hermetic, ceramic military parts are going away. It is only a matter of time. At this point, ceramic packaged parts come from assembly and test houses with uncertain process control and discontinuous assembly, both of which are highly conducive to low as-manufactured quality. To use these parts, quality will have to be "inspected in." In all likelihood, both commercially manufactured ceramic packaged and radiation hardened parts as well will disappear before the end of the century. There is no denying that this is the future.

The question then becomes, how will we build reliable weapon systems in the future with the components that will be available?

Here are several approaches that have been proposed by SNL planners.

"Stockpile all the Mil Spec and rad hard parts you will ever need now and use them to build future weapon systems." The obvious problem with this approach is that we will eventually run out of parts and will soon be building our new designs only with obsolete or discontinued components. There is also a concern about the eventual shelf life of stockpiled components.

"Depend upon the US government to support a dedicated manufacturing facility that will build Mil Spec, space qualified and rad hard components." This option is not currently in the works, and its happening is not assured in era of a diminishing federal budget and the Perry Initiative. A strategy critically dependent upon this approach would be risky.

"Industry will have to continue to supply mil/space/rad hard components." This approach is a pipe dream. It amounts to solving the problem by denial. When I posed it to Weldon Beardon, Texas Instruments, Military Products Division engineering manager of Known Good Die and Multi Chip Modules, his response was one word, "Why?" TI will eliminate 
military products "in a heartbeat" the moment they become unprofitable and devote the small amount of additional $\mathrm{Fab}$ time they would recover to making profitable commercial integrated circuits. Furthermore, pleas from TI for OEMs who supply product to the $\mathrm{DoD}$ to make use of new "QML" parts made in plastic are falling largely on deaf ears. It seems to be a "chicken and egg" situation. There are only a handful of parts available, so almost no one is using them, so TI and the other potential manufacturers are not making any more parts available.

So what do we use for components to build weapons when our traditional components disappear? The formerly unthinkable alternative may indeed become the only long-term sustainable solution, we will have to use Commercial Components!

Non-military companies have been using "Commercial grade, Off The Shelf" (COTS) Components for decades to build highly reliable systems. The consequences of failure are not as serious as accidentally blowing up Albuquerque, but they do involve for example the loss of telecommunications for large cities or portions of the country, the loss of ability to conduct the business and financial affairs of industry, or the loss of avionics systems on commercial airliners. (Yes, that Boeing 737 that you fly to San Francisco or to Kansas City is using plastic components in its avionics packages! And there is no more redundancy built into its plastic component system than is in earlier systems made from Mil Spec ceramic components.) The penalties for such failures can be calculated, and they run to millions of dollars and potential loss of hundreds of lives for short service outages.

Commercial experience with large, complex systems in field environments has demonstrated that: 1) COTS components in controlled and uncontrolled, ground based field environments are demonstrating FIT rates on the order of 0.1 to 3,2 ) COTS components are being designed into telephone and missile equipment that will be in the field for 20 to 25 years of service life, 3) COTS components now flying in commercial aircraft environments are behaving as well as hermetic, ceramic packaged parts in the same applications.

The DoD has sponsored a 2 year; 2 million dollar study of the applicability of plastic encapsulated, Commercial Components to military environments. The answers are in the final stages of being formulated, but the message is clear. Operated within the true limitations of their packaging and of their design, which are not necessarily as stringent as the limits stated in their commercial specifications, COTS components can be qualified to provide the service and reliability required of military product.

So even if it flies in the face of all conventional wisdom, let's examine the status of Commercial Components to see if they might have a place in the answer to what we are going to do for components in the future. 


\section{Case Studies involving field experience with Commercial Components}

To gain some insight into the quality and reliability that can be obtained from Commercial Components, let's look at the experience of several companies that have been using them.

\section{Factory and Field Experience with AT\&T WP Components}

For decades, AT\&T has operated a company wide Component Management and Procurement System to obtain commercial parts that it does not itself manufacture. The current system is called the WP Specification Program. WP components are straight, commercial designs. AT\&T qualifies all manufacturers who supply WP components and the component types or families that they buy. We have been working recently with AT\&T to evaluate the performance of these WP components so that we might better understand what is to be expected of COTS components.

Analysis of AT\&T's field experience database demonstrates that, at this point in time, the majority of observed failures are caused by 1) latent defects introduced in component manufacturing that are not related to the component design intent or to the traditional, "physics of failure" modes that cause long term degradation of the component, 2) environmental shock, and 3) inadvertent component application blunders (overstress). In the AT\&T world, failures due to "Production Agency" manufacturing processes which assemble the components into "next assemblies" and to known, physics-of-failure modes within WP components are "down in the noise."

AT\&T field failure rates due to component latent defects are extremely low, in the sub parts per million area. Doing Incoming Inspecting on millions of components to find one bad one would induce more failures than it would remove. AT\&T manufacturing locations made a business decision to stop doing regular incoming inspection around 1990 when indicated incoming quality levels were below $50 \mathrm{ppm}$ defective. Instead, they weed out bad components at first test after assembly and in system burn-in, when it is done. Early field failure rates for WP components from 2 years of warranty data (infant mortality portion of the bath tub curve) are estimated to be as good or better than Mil Spec components which run around 1 FIT (1 FIT is one failure in $10^{9}$ operating hours) in controlled and uncontrolled environments. These extremely low failure rates are representative of the front edge of the bath tub curve! (and of what AT\&T's Component Management Program is delivering, and of the fine process control maintained by AT\&T's manufacturing.) Mid life reliability will be this low or better!

In the opinion of AT\&T Reliability Professional Michael Tortorella, who provided the above study, industry has learned how to design and manufacture commercial components that are so robust that failure modes due to understood, physics-of-failure problems are not relevant in 20 to 25 years of field operation within the component spec ratings. (He says 20 to 25 years because that is the typical service life of a major AT\&T system, not of the components.) Statistical studies of field reliability have just about reached their limits. Field failure rates are so small that even within the giant AT\&T 
database, only first order, overall trends can be determined. Analysis of individual failures for cause determination and correction is currently being done.

Since overstress due to inadvertent component application blunders is now the way wearout failures are stimulated, AT\&T is working toward a Best In Class Practice, an automated, $\mathrm{CAD} / \mathrm{CAE}$ design audit that will compare component use in the circuit being designed to the recommended guidelines derived from the manufacturer's rating and the basic physics of component failure for those components. AT\&T is working toward a close relationship between the system designer and the component supplier so that component stress levels can be optimized for best reliability.

Finally, in a comparison which is quite relevant to our own DOE component procurement experience, today's AT\&T Managed WP COTS components are achieving better field reliability than did their heavily inspected and "certified" (each component tested and accepted per a Source Controlled Drawing) Submarine Cable components 10 years ago.

Honeywell Comparison of Field Reliability of Commercial Plastic IC's and 883B Ceramic IC's operated on Commercial Aircraft

The Plastic Package Availability Program (PPA) is a $\$ 2$ million Tri-Service sponsored effort funded through the Defense Logistics Agency. Its objectives and goals are to investigate contemporary technology and provide a better understanding for the potential use of plastic-encapsulated microcircuits in military systems. Honeywell is one of the "Performing" partners.

As part of the PPA, Honeywell surveyed the performance of plastic packaged, surface mount parts (used since 1990) and of ceramic packaged parts in the same air transport avionics systems flying in Boeing, Douglas and Airbus aircraft. Typical air transport requirements are 10 hours per day in the air, 335 days/ year (Northwest 757), 20 year life, vibration $3 \mathrm{~g}$, box ambient temp -40 to $+70^{\circ} \mathrm{C}$ (parts ambient goes up to 85 to $90^{\circ} \mathrm{C}$ ), humidity 0 to $100 \%$. The ceramic parts are Mil $883 \mathrm{~B}$ grade. The plastic parts are commercial parts purchased from suppliers selected for their in-place Statistical Process Control and "constant improvement" mindset, and for their willingness to demonstrate with data that a quality product is being consistently produced. These suppliers have an agreement with Honeywell for consistent notification of all changes made in their products.

Honeywell puts a five year warranty on all of their systems, and they do all repairs during the warranty period, so they have a complete database for this study.

Honeywell's study as reported by John W. Fink in August, 1995 finds the failure rate of digital SSI/MSI and $\mu$ Processor/Memory in plastic to be half that of the same parts in ceramic. 
Some persons experienced in the field of military component reliability have a difficult time understanding how it is possible for commercial components to be better than Mil Spec components. They argue that commercial components might be (almost) as good as Mil Spec components, since in most cases the die are the same, but that it is not logical, does not follow from principles of physics, that they should be better. I posed this question to John Fink; and his reply, drawn from engineering as opposed to physics, is that it is not surprising that commercial components should be better. Except for TI which is QML, Mil Spec parts are being made on process lines approved by DESC. These lines cannot be changed without authorization from DESC which is quite difficult to obtain. Commercial parts, on the other hand, are being made in much greater volume and with much greater net profit to their manufacturers on lines that the manufacturers are constantly investing talent and money to improve. John argues that commercial components should be expected to have better yield and fewer manufactured-in, infant mortality causing defects than do Mil Spec components.

The failure rate of linear parts in plastic, as John reported in August 1995, was thought to be three times that of the same parts in ceramic. However, since that time a more careful failure analysis has been done. Half the linear "failures" are one part from one manufacturer. Those parts were "upscreened" from commercial grade, $-40^{\circ}$ to $+85^{\circ}$ parts. Analysis shows those parts still meet their specification in the $-40^{\circ}$ to $+85^{\circ}$ range. John Fink's conclusion is that this represents an "application problem" rather than a component failure.

In any event, using a "typical" system weighting of the mix of digital and analog parts, Honeywell's conclusion is that, for the Commercial Avionics environment, plastic surface mount IC's are more reliable than $883 B$ ceramic DIP's.

Honeywell is using mostly 0 to $70^{\circ} \mathrm{IC}$ 's screened to -40 to +125 . They started with a 160 hour lot burn-in, rejecting the lot on one failure. A lot, at customer Boeing's insistence, consisted of 2000 parts of 3 different date codes (to insure supplier consistency across manufacturing lots). But they found no rejects, so they reduced to lot sampling. They finally stopped burn-in to "prove-in" plastic parts because it was over stressing them. Their study showed that unscreened plastic parts show considerably better field reliability than the screened plastic parts!

For temperature range assurance, they sample test a lot. . Fallout is about $1 \%$ to the extended temperature range. Honeywell avoids overall lot screening because test houses induce failures. Test houses don't know how to test high speed logic.

The cost advantage to plastic, surface mount is overwhelming. 16 cards shrink to 4 , they can use automated assembly, there is less test and handling. Component costs are lower by a factor of ten.

Honeywell talks to their customer, Boeing, on a consistent basis. Boeing Commercial Aviation systems also makes avionics boxes, but they have no service centers so they do 
not get the same amount of data as does Honeywell. Still, John Fink of Honeywell quotes his Boeing contact as saying that, "As far as we know there's no problem out there." To Boeing, the field reliability of plastics and ceramics looks the same.

\section{ITT's Commercial Parts Program Plan Implemented in SINCGARS and MINTERM}

ITT has designed, built, and is now successfully shipping SINCGARS, a ground mobile and Army helicopter airborne radio system, and MINTERM, an analog and digital voice and data encryption device for ground mobile service, using production hardware populated with non military components. Both of these programs had formerly been built with military components. Use of selected commercial parts from qualified manufacturers is transparent in manufacture. System failure rates in Pilot Evaluation are half that predicted by Mil Handbook 217. There are no field failures in $16 \mathrm{~K}$ and $15 \mathrm{~K}$ operating hours respectively. Performance, Quality and Reliability using Commercial Parts is transparent.

ITT is presently developing AIRTERM, an airborne version of MINTERM, using commercial components.

\section{General Dynamics Implements SINCGARS using Best Commercial Practices}

General Dynamics is also making SINCGARS. They have established a parts control program, qualified suppliers and done over 9 million hours of qualification testing. Like ITT, they are using primarily commercial parts rated from -25 to +85 or -40 to $+85^{\circ} \mathrm{C}$ and lot sampling to assure that they meet the wider limits required. They find that careful program planning and execution coupled with extensive system level testing of components provides Best Commercial Practice parts that are as robust as their traditional Military counterparts and result in from $50 \%$ to $70 \%$ cost savings.

Rockwell International, Collins Avionics Division, Uses Plastic Encapsulated Microcircuits in Precision Lightweight Global Positioning Receiver

Rockwell/Collins Tri-Service Precision Lightweight Global Positioning Receiver (PLGR) made from surface mount, commercial PEM's, initially went to the field in 9/93. There are now $35 \mathrm{~K}$ units in service. Environmental requirements include $-20^{\circ}$ to $+70^{\circ} \mathrm{C}$ (but they operated to $-40^{\circ} \mathrm{C}$ at last year's Winter Olympics), humidity, vibration, and salt fog. Reliability has been demonstrated by the US Army, with an 11,514 hour point estimate for MTBF (based on 1 observed failure). Cost savings were 8.5:1 over Mil Screened parts, but use of mil parts would require redesign for through-hole technology and increase the unit size. No formal qualification process was used on suppliers, they were selected on basis of experience. After 254 million component hours, the Worst Case Failure Rate (counting 38 ASICs whose FMA is in progress as all bad for total of 46 PEM failures) produces a rate of 0.181 failures per million op hours. This is at least $60 \%$ lower than Mil Handbook $217 \mathrm{H}$ prediction. Overall failure level is approximately equal to that predicted for mil screened parts. The final report on their 18 month case study to assess 
quality and reliability of PEM's and to determine field failure mechanisms is due in June, 1996.

\section{Lucas Electronics Experience with Civil Engine Control Reliability}

Lucas Electronics is a large, multinational company located in Birmingham, England, with 46,000 employees. It does $\$ 860$ million business in Aerospace and $\$ 2900$ million in Automotive sectors. Lucas makes electronic control systems for civil airplane engine control (in ceramic, Mil Spec parts) and for automotive engine control (in plastic COTS). Automotive environments are comparable to airplane environments, and Mil Spec and plastic COTS component failure rates are also comparable $(0.01$ to 0.04 failures per million operating hours ). Lucas is evaluating plastic encapsulated devices for use in aerospace systems.

Computing Devices International sees using commercial technology for military applications as a business necessity.

CDI is a relatively small, Minnesota based manufacturer of shipboard and Navy airborne computer equipment. They won the Minnesota equivalent of the Baldrige award in 1995. Maurice Chener of CDI presented this information at the SHARP conference. In May, 1995, they began to ship a new Mark 162 system made from commercial parts that is fully plug-compatible with a 10 year old AN/UYK-44 unit. The new system is $3 / 7$ ths the weight of the old, faster, has greater disc capacity, the same MTBF and costs $\$ 90 \mathrm{~K}$ instead of $\$ 175 \mathrm{~K}$. It works in the same -55 to $+125^{\circ} \mathrm{C}$ environment. They are just beginning delivery of another system based on the Power PC that has an 8:1 speed advantage when running $\mathrm{ADA}$ and a 16:1 advantage when running aircraft software for half the price of the former version.

CDI sees meeting both hardware and software obselescence problems the same way the commercial world does, by introducing better, faster, cheaper products now and by replacing them in the future with plug compatible units using the next generation technology.

MATRA Defense (France) has been using plastic parts since 1987 in Missile applications.

The presentation that I heard on this topic was one of those where I understood the individual words but I missed most of the meaning. Something was obviously lost in the translation. They were delivered by M. Michel Barre, Prospective \& Research Group Manager for Electronic Parts, MATRA Defense. But the headline tells the message, plastic parts have been used successfully in French Missile applications since 1987. 
British Defense Research Agency, Space Department, will Investigate COTS for Use in Spacecraft

After hearing the above reports, the British Defense Research Agency is preparing to investigate Best Commercial Practice and Commercial Off The Shelf components for use in spacecraft. They will be placing a contract in April 1996.

The above Case Studies certainly suggest that commercial, plastic encapsulated components are capable of functioning successfully in at least some high reliability and military environments. Let's look at other issues brought up by the experience of these and other companies that have been using or making COTS components.

\section{Incentives to use Commercial Components}

The above companies and other Military and Aerospace OEM's have contributed to the following list of incentives to use Commercial Components.

- There is an immediate order of magnitude savings in just the cost of components.

- New technology is available first, and often exclusively, in commercial parts.

- All high volume microcircuits plus $95 \%$ of world semiconductor production is available in plastic packages.

- Commercial components are readily available (although some are on allocation).

- Commercial packages allow systems to be substantially smaller and lighter.

- Commercial components can be assembled on six sigma commercial manufacturing lines.

\section{Potential Problems with Commercial Components}

These same sources also agree that much more care must be put into the selection of the appropriate component to fit the application. It's no longer as simple as it once was when a hermetically sealed, ceramic packaged, Mil Spec qualified component could be put into a wide variety of environments and counted on to work. The same sources note the following problem areas that must be addressed when using Commercial Components.

- Commercial parts are not intentionally radiation hard. (This is a problem for which there is no single, neat solution. There are circuit improvements that can be made. There is a package shielding material that can be used with commercial die and is rated to $100 \mathrm{~K}$ rad total dose. The manufacturer, Space Electronics Inc., San Diego, is working with Lockheed/Martin and JPL. The rad hard problem is going to require a lot of attention from Aerospace and Weapons designers.)

- Commercial parts will often be required to operate beyond their specified temperature range. Honeywell has demonstrated that it can be done, that most commercial parts do not degrade precipitously beyond their specified temperature range. But there are caveats from the manufacturers. 
- Commercial die will change on average every 18 months. Both masks and processes will change. This will be a problem if a part is used beyond its commercial specification or if "qualification" of a part is required.

- The lifetime of commercial designs is generally shorter than that of mil spec designs. This will exacerbate field replacement problems.

- Manufacturers will save old military die for years, but they do not save commercial die. (A counter to this is that many manufacturers no longer make separate military die.)

- Commercial manufacturers will not (readily) accept source control drawings. They have a "take it as it is" attitude.

- It is sometimes difficult to get change notices from suppliers. An OEM who uses a third party assembly house may not purchase components and so doesn't look like a customer to the supplier.

\section{Long Term Storage and Use Reliability of Commercial Plastic Components}

As part of the DLA sponsored, Tri-Service Plastic Package Availability Program mentioned above in conjunction with the Honeywell case study, Patrick McCluskey, University of Maryland, CALCE Electronic Packaging Research Center, supported by an Army Research Lab CRADA and assisted by 36 Corporate Members, has been doing an ongoing study into the effects of storage on Plastic Encapsulated Microcircuits. Three sets of components, both plastic and ceramic packaged, are being evaluated, a group of IC's stored in a distributor's warehouse for 12 years, a group of IC's assembled onto commercial printed circuit boards and either used in a variety of environments or kept in storage for 9 to 12 years, and a group of IC's installed in 15 year old military Sonobouys. He is examining the samples with a variety of electrical and non-destructive testing techniques and then using HAST (Highly Accelerated Stress Testing) to estimate their remaining life.

Thus far, no catastrophic problems have been found in any of the parts. He estimates that the average life of the components stored in the distributor's warehouse due to all wearout mechanisms exceeds twenty years.

Although we have not yet probed the AT\&T database for long term operational reliability data, Michael Tortorella of Bell Labs has identified data from 4 ESS and 5 ESS Switching Systems and from remote terminal units that dates back as much as 15 years. He has offered, for a price of course, to analyze this database for us. This would give us another look from a much larger database at the same question.

The above information, while not complete, strongly indicates that there is no major problem with plastic parts in dormant storage where the ambient humidity is not excessive. Westinghouse Electric Corporation in Baltimore is beginning a study of Long Term Dormant Storage Reliability of Plastic Encapsulated Microcircuits. Their objective is to develop a physics of failure model which will relate Highly Accelerated Testing using 
Temperature and Humidity but not bias as stresses to long term, dormant storage of modern components in conditions of known humidity and temperature. This and other work in progress should answer the remaining questions in this area.

\section{Advanced Silicon Based Thin-Film Material Provides "Hermetic Seal" for Semiconductor Devices.}

Dow Corning has developed a thin film, "molecular designied silicon material" (which I believe is a Silicon Carbide ceramic coating) that their tests show approaches hermetic package behavior in a temperature-humidity soak/temperature cycle $159^{\circ} \mathrm{C}$ HAST testing sequence. For this test, leadframe mounted National Semiconductor die were ceramic coated and then molded in 95 mil thick plastic surface mount packages by National. Their "ChipSeal" process can be applied at the wafer level as well, but that will not protect the bond pads which are most vulnerable to corrosion during HAST. The current cost for application to a 6 inch wafer is about $\$ 300$. In those cases where the harsh storage or operating environments are a problem that conventional plastic packages cannot handle, this process may provide an alternative if ceramic packaged, hermetically sealed devices are not available.

\section{Recommended Design Process and Supplier Selection Guidelines when Using Commercial Components}

The following Design and Supplier Selection Process outline was contributed by Lou Zampetti of Lockheed/Martin Missiles Systems Division, Sunnyvale. It is typical of processes being used by Lockheed and other companies who are using Commercial Components in military designs.

\section{Lockheed/Martin Missiles System Division Recommended Design Process:}

- Get the circuit designer to define functional needs (rather than say I want that Mil $\mathrm{Spec}$ ). That plus reliability and environment becomes your requirements.

- Create Design Team with parts engineer, mechanical engineer, designer, system engineer. They all sign off on parts and system.

- Phase 1: Demo design concept and technology. Go to supplier capable of QML quality, even if you get only distributor parts.

- Phase 2: Tie into your supplier's process and mainstream (QML) products.

Supplier will continue to develop and support those process and products for the commercial market.

- Go with those suppliers and their commercial parts for $80-90 \%$ of your parts. Only a few special problems left, solve with ASICs.

- Avoid extreme requirements.

- Add military/environmental/reliability requirements.

- Avoid Source Control Drawings!

- Deal with the supplier, use his standard product and part number, don't overload him with paperwork and government purchasing requirements. 
Honeywell, Military Avionics Division provides the following.

Honeywell Supplier Selection Guidelines

- Be careful from whom you buy.

- Some junk peddlers are on the DESC good supplier list (die problems).

- Team with supplier, get lots of data.

- Automatic change notices are not dependable. Be aggressive about getting them.

- Find a supplier with good SPC, backed by supplier's data.

- You will want parts to work over our temperature range, regardless of the data sheets. Most commercial parts will work over -55 to +125 . Lot sample to verify.

And several other DoD OEM's have contributed to the following list of Supplier Evaluation Guidelines.

\section{DoD OEM's Supplier Evaluation Guidelines}

- Use qualified suppliers and parts (previously qualified to Mil Spec).

- Use die characterized for mil/industrial grades.

- Assure design margin (the subject of several Best Practices to be mentioned later).

- Use circuit simulation and modeling.

- Ask supplier if parts will work in your application.

- Talk to other users.

- Record all information on a given part.

- Take advantage of new technology.

- Ring out and eliminate problems with Environmental Stress Screening approach. (Another Best Practice)

Ron Kovacs, National Semiconductor program manager for the Plastic Package Availability Program, recommends the following list of Do's and Don't's for the qualification, procurement and use of plastic packaged parts summarized from the Program experience.

\section{PPA Program, Recommended DO's}

-Use non-aggressive fluxes to solder plastic encapsulated microcircuits (PEMs) to printed wiring boards.

- Favor a mold compound with ionic getters.

- Use preconditioning for PEM qualification to simulate worst case assembly and repair conditions.

- Use Biased HAST Qualification for moisture intensive applications.

- Qualify mold compound changes.

- Qualify PEMs by Vendor, Package, and Chip Family. 
- Qualify larger chips ( $>250$ mils per side) with temperature cycling and inspect for chip cracks.

- Use low stress $\left(<35 \mathrm{kpsi} /{ }^{\circ} \mathrm{C}\right)$ mold compound for packages with more than 68 leads.

- Design for lowest practicable operating voltage.

- Qualification conditions should be at the application's highest operating voltage.

- For extended PEM life, design for lowest storage and operating temperatures.

- Consider hermetic ceramics for critical, long term, harsh environment applications.

- Use 3 temperature screen (low and high extremes and room temperature) and burn-in if you want High Reliability - as you would do with hermetic ceramic parts - with the approval of the manufacturer.

- Use sensor chips for package evaluation available through the Sandia User Facility.

\section{PPA Program, Recommended DON'T's}

- Don't use PEM's for long term, high moisture operating conditions, especially with high voltage and temperature.

- Don't use aggressive flux during assembly or repair.

- Don't use high stress mold compound with large chips (>250 mils per side).

- Don't use PEM's beyond the manufacturer's maximum ratings - without working with the manufacturer and running a qualification.

- Don't run environmental life test qualifications without first preconditioning a PEM.

Cliff Schawch, Rockwell, reported the recommendations of a PPA Program Multi-Use Manufacturing Work Panel on Commercial IC's in Military Applications. The Panel advised the following:

PPA Priority Sequence for Selecting Components.

1) Select parts from a commercial catalog. Use those with published data that meet the environment.

2) Go to QML surface mount devices.

3) Go to Mil Spec, QPL devices (but slowly dying, won't be available long term).

4) On any part, if use is outside spec range, test in the use environment (designer involved). How and what to test is a matter of engineering judgment and technical risk.

The Panel further concluded that:

- The use of Commercial IC's is broadly practical.

- Commercial IC's are readily available. 
- Commercial IC's can be used if screened or tested (in cases where specs are insufficient).

- Not cost but availability is the major driver toward the use of Commercial IC's.

And finally, for a comprehensive coverage of guidelines for the selection of commercial/industrial, commercial (consumer), and traditional military microcircuits for military equipment, there is the new Mil Handbook 179A, released 7/20/95, that presents a Parts Control Program Plan and Selection Criteria for Suppliers and for Parts.

\section{Adoption of Commercial Best Business Practices}

With defense OEM's adopting the commercial components used by their commercial corporate cousins, they have also picked up some Commercial Best Business Practices. TRW has provided an example.

TRW Avionics and Surveillance Group is running a pilot program within the Air Force Manufacturing Technology Directorate's Industrial Base Pilots Office. The program will demonstrate "dual use" manufacturing by producing F-22 and RAH-66 Comanche Helicopter military avionics modules (2) on a commercial TRW automotive electronics manufacturing line. This requires redesign of the modules so that they can be produced with commercial processes, and establishing compatible business policies and practices, manufacturing infrastructures and process technologies.

Adopting the commercial process yields cost savings in material, labor (inspection), overhead (contractual obligations, quality systems). Assembly tooling is more expensive because products are made on automated line instead of by hand.

So far, TRW has completed phase 1 - planning, conceptual design, business practices. They are running a reliability test of 65 modules built at their commercial plant using a Design of Experiments test matrix. Results will be complete in October, 95. They have achieved a $41 \%$ cost reduction, a 19\% weight reduction, and their life estimate exceeds 2 lifetimes.

The TRW Avionics and Surveillance Group has adopted a new business paradigm involving concurrent engineering utilizing their (commercial) computerized design/manufacturing system and real time data base.

TRW sees the result of their new paradigm being a four win scenario, for the F22 and Commanche (Mil program office), for the Air Force Manufacturing Technology, for the Commercial Manufacturer who will be able to use military products to increase the fill factor of his line, and for the DoD.

Changing manufacturers, Honeywell has recommended a Best Practice that they are using. They "require, as a part of the standard design process, that all products designed and built by Honeywell's Commercial Aviation Systems -Sensor Products Operation (CAS- 
SPO), meet Honeywell's derating criteria. The purpose of component derating is to optimize the reliability of Honeywell designs."

Another Best Practice similar to Honeywell's that Sandia might well be interested in is suggested by AT\&T. They are introducing a CAD/CAE automated design review of all new electronic designs that determines whether each component is being operated (stressed) within the manufacturer's ratings and whether its level of stress is consistent with AT\&T's understandings of physics of failure mechanisms.

\section{A Semiconductor Manufacturer's View of the Perry Initiative and the Military Switch to PEM's}

In this environment of rapid change, not everyone sees the entire picture or perceives things the same way. Buf Slay, Military Products QRA Manager, TI, Military Sector, provided the following comments under the general heading of "Best Commercial in Military Semiconductors." His stated intent is "to show areas where commercial plastic has performed well and areas where commercial plastic has had problems."

The Perry Directive calls for Performance specifications and standards. QML is an umbrella performance specification that allows building of several types of parts, plastic and hermetic. Offshore wafer Fab is approved for QML parts. There are 7800 devices currently available under QML, including 20 plastic packaged parts with the -55 to $+125^{\circ} \mathrm{C}$ temperature range. In contrast, commercial components are rated for a 0 to $70^{\circ} \mathrm{C}$ temperature range. The parts are the same, sometimes.

QML parts offer several advantages to the user. There is Traceability on QML parts. DESC is certifying suppliers of QML parts, including plastic parts. Military parts offer obsolescence control, the manufacturer keeps old die for military parts but not for commercial parts. Vendor support levels will be significantly lower for commercial plastic parts than for QML parts.

Many but not all QML parts share the same die with commercial parts. There are several parts that have had to be modified to meet the full range of Mil Spec requirements. Buf also acknowledges that Honeywell has found only about $1 \%$ fallout when testing commercial parts to the full Mil Spec temperature range.

(In this regard, in a separate conversation with Nick Lywudes of Motorola, I was told that if there are bandgap references in a device, it may have to be redesigned larger for it to operate in the lower temperature range. In general however, there is no problem in using parts over a greater temperature range if you characterize them. Parts don't fall off a cliff, their margins or parameters just change a bit. Manufacturers don't have the equipment necessary to run assurance tests, required on 1 of 10 lots, so they will not guarantee their parts beyond the commercial spec range. Motorola will sell the center of their microprocessor distribution to a customer wishing to achieve a -55 to $+125^{\circ} \mathrm{C}$ range in plastic.) 
Unfortunately, the QML program seems to be in a "chicken and egg" situation. Because there are so few plastic packaged parts currently available under QML, customers who want to use plastic parts are not turning to the program for them. Because of this, more plastic parts are not being added to the program. QML would provided added value for at least some military users for a premium price. QML plastic parts are approximately 2.5 times more expensive than commercial parts. Buff Slay disagrees with Cliff Schwach's panel recommendation. He would rather see QML parts be the first option. Whether the program will become a viable source for plastic parts remains to be seen.

Plastic surface mount parts require careful storage, handling, and processing. But they can obviously be processed successfully.

Vendor Selection is critical for plastic parts. Not all suppliers are equal. There is a wide range of HAST behavior on similar packages made by different vendors. While long term reliability of plastic parts may be acceptable in some military systems, it may not be as good as hermetic parts. Where plastic parts are used in suitable environments, however, operating life tests show that their reliability is now equal to that of ceramic parts.

The military market is dropping as a percentage of the total, but it is still $\$ 1.4$ billion per year. (However as I mentioned in the introduction, Weldon Beardon, TI Military Products, Known Good Die and MCM Engineering Manager, also told me that if the Military Component Division of TI becomes unprofitable, it will be dropped "in a heartbeat.")

\section{Plastic Package Availability Program}

As mentioned earlier in conjunction with the Honeywell case study, the Plastic Package Availability (PPA) Program is a \$2 million Tri-Service sponsored effort funded through the Defense Logistics Agency. Its objectives and goals are to investigate contemporary technology and provide a better understanding for the potential use of plastic-encapsulated microcircuits (PEM) in military systems. "Performing" partners include NSWC-Crane, Dow Corning, Honeywell, and Plaskon Electronic Materials. A Government Steering Committee comprised of the Air Force (Rome Labs), Army (MICOM), Navy (Crane), DLA/DESC, and NASA (Goddard) has been very much involved in helping direct the planning and execution of many of the tasks.

In addition to the main thrust of evaluating PEMs via accelerated life-testing; moldcompound material studies, sensor development, and fielded system failure analysis comprise a comprehensive program. Both high lead-count (68L-PLCC) and low leadcount (14L-MDIP, -SOIC) package form factors are used with 8 different moldcompounds, manufactured on an off-shore standard production line. Other variables being studied are operating voltage and preconditioning (board simulation pre-stress). A unique moisture/corrosion stress sensor chip was developed by SNL under this program and is included in several of the life tests, side-by-side with the product test devices. Data from 
fielded avionics systems has been collected and is being analyzed for failure rates and comparison of device technologies and package types.

The program is planned for completion in the fall of 1995 with most life tests well along and failure analysis initiated on those failures generated to date. A full day program final review was presented on 11/15 and 11/16 at the Navy-CRANE sponsored "SHARP Conference." Some of the information in this report is taken from notes made at that conference. A full published report is due early in 1996.

\section{And Finally, a Sandia Perspective}

As I was wrapping up my surveys for this paper, I called Sandia's own Dave Peterson, who has been participating in the Plastic Package Availability Program and has designed their special stress sensor chips, for his perspective on the use of commercial, plastic parts in Sandia's weapon systems. Dave's remarks in several ways form a fitting conclusion for all of the above material.

Best Commercial Practices on plastic encapsulated microcircuits have evolved to the point where we now have cleaner materials, less stress and wafer fabrication and packaging lines running at six sigma control limits. Plastic parts are proving to be very reliable, even under HAST. There are greater problems with plastic packages than with hermetic packages, but they are all workable.

We have to readjust our thinking about what HAST means. Although we don't normally test hermetic parts in HAST, we would consider any failure unacceptable. The same does not apply for plastic packages which are sure to fail given sufficient time and acceleration. The HAST conditions routinely used by manufacturers and experimenters on high quality plastic parts in order to see representative failures are so severe that few give credence to traditional Arrhenius relations correlating accelerated life to real life. Most commercial manufacturers use HAST as a development tool and performance benchmark. They know how long good product will last under HAST, and use it as an indication of their process control. The key is to understand the performance limitations on a part-by-part basis and make sure that they fit the application.

Mil specs are disappearing. We should go to Automotive and Aerospace users, see how they manage to use plastic parts and learn from them. We will have to buy parts rated to $+85^{\circ}$ and test them to $+125^{\circ}$. We will have to know our suppliers and their statistical process control. We will have to deal with distributor issues. It will require a lot more management of our component procurement system.

On a case by case basis, plastic packaged parts are suitable for weapons systems. It is only a matter of time before both DoD and DOE will be using them. They are coming around because they have to. The next new DOE weapon system will contain commercial plastic parts. 
Distribution:

\begin{tabular}{|c|c|}
\hline 070 & R. E. Bai \\
\hline 1071 & T. A Dellin, 1203 \\
\hline 0523 & C. F. Gibbon, 1204 \\
\hline 1071 & T. J. Allard, 1205 \\
\hline 0527 & E. P. Royer, 1231 \\
\hline 0525 & T. Fischer, 1235 \\
\hline 0523 & J. O. Harris, 1251 \\
\hline 0523 & L. R. Edwards, 1251 \\
\hline 0525 & L. S. Curtis, 1252 \\
\hline 0525 & J. T. Hanlon, 1252 \\
\hline 0525 & D. K. Kramer, \\
\hline 0525 & J. E. McKenney, 1252 \\
\hline 0525 & P. V. Plunkett, 1252 \\
\hline 1073 & W. J. Barnard, 1272 \\
\hline 1072 & F. W. Hewlett, Jr, 1273 \\
\hline 1072 & K. K. Ma, 1274 \\
\hline 1081 & R. E. Anderson, 1275 \\
\hline 1081 & J. M. Soden, 1275 \\
\hline 1081 & R. V. Baron, 1276 \\
\hline 1081 & W. M. Miller, 1276 \\
\hline 1073 & P. Dressendorfer, 1277 \\
\hline 1083 & P. S. Winokur, 1332 \\
\hline 1082 & D. R. Johnson, 1333 \\
\hline 1082 & D. W. Palmer, 1333 \\
\hline 1082 & son, 1333 \\
\hline 0501 & P. J. Wil \\
\hline 9405 & D. L. Li \\
\hline 1434 & D. F. Mo \\
\hline 0456 & D. L. McCoy, 2100 \\
\hline 0435 & F. F. Dean, 2102 \\
\hline 0484 & R. G. Bradley, 2103 \\
\hline 0427 & W. R. Reynolds, 2103 \\
\hline 0475 & D. O. Tipton,2105 \\
\hline 0560 & P. A. Longmire, 2106 \\
\hline 0447 & J. O. Harrison, 2111 \\
\hline 0487 & J. D. Mangum, 2121 \\
\hline 0487 & J. D. Porter, 2121 \\
\hline 0486 & W. D. Chadwick, 2122 \\
\hline 0482 & A. B. Cox, 2161 \\
\hline 0483 & R. L. Alvis, 2165 \\
\hline 0445 & O. Brooks, Jr, 2166 \\
\hline 0445 & R. C. Hartwig, 2166 \\
\hline 0445 & T. F. Hendrickson, 2166 \\
\hline 0481 & M. A. Roseṇthal, 2167 \\
\hline 0481 & V. Willan, 2167 \\
\hline 1393 & P. G. Heppner, 2200 \\
\hline 9006 & D. J. Bohrer, 2203 \\
\hline 9036 & D. Gehmlich, 2254 \\
\hline 9036 & D. R. Henson, 2254 \\
\hline 9036 & M. Hinckley, 2254 \\
\hline & \\
\hline
\end{tabular}

9036 S. Vasey, 2254

9034 D. J. Beyer, 2263

9034 D. B. Starkey, 2263

0537 D. D. Huffman, 2314

0537 M. J. Mundt, 2314

0505 G. M. Heck, 2334

0503 B. D. Shafer, 2335

0505 D. L. Eilers, 2336

0533 R. E. Heintzleman, 2343

0533 W. R. Sceiford, 2343

0533 W. H. Schaedla, 2343

0529 J. D. Bentley, 2346

0529 M. B. Murphy, 2346

0987 R. J. Longoria, 2611

0519 D. A. Branscombe, 2612

0519 M. M. Contreras, 2612

0519 R. J. Kujlu, 2612

0519 S. J. Lesle, 2612

0519 S. Theriot, 2612

0535 L. J. Dalton, 2615

0329 R. S. Urenda, 2643

0319 W. R Leuenberger, 2645

0986 E. R. Kadlec, 2663

0987 D. E. Ryerson, 2664

0986 T. R. Perea, 2665

0311 J. W. Hole, 2671

0311 G. R. Lyons, 2671

0328 J. A. Wilder, 2674

0458 L. R. Gilliom, 5133

9141 A. F. Baker, 5209

0767 E. R. Hoover, 5503

0967 J. H. Borego, 5706

0967 J. F. Hudson, 5706

0967 L. W. Maschoff, 5706

0967 P. A. Snipes, 5706

0966 S. A. Spraggins, 5717

0972 A. J. Medina, 5722

0815 J. L. Russell, 5932

0877 M. D. Terry, 5933

9141 R. L. Rinne, 8104

9104 M. H. Rogers, 8210

9405 C. F. Acken, 8220

9101 W. C. Peila, 8411

9406 H. H. Hirano, 8412

9102 A. L. Hull, 8416

9106 P. R. Bryson, 8417

0202 G. L. Record, 10250

0830 N. D. Magnuson, 12335

0830 J. M. Sjulin, 12335

0637 E. L. Saverino, 12336

1068 J. B. Woodard, 14003

0560 C. A. Murray, 14004 
10863 G. M. Furguson, 14309

19018 Central Technical Files, 8523-2

50899 Technical Library, 4414
10616 Print Media, 12615

20100 Document Processing, 7613-2 For DOE/OSTI 